\title{
The Borderless Integration of Financial Management Innovation Using Big Data Analysis of Social Media
}

\author{
Jinghui Tang $(\mathbb{D}$, Chunling Li, Ying Fu, and Chu Li \\ School of Economics and Management, Yanshan University, Qinhuangdao, Hebei 066004, China \\ Correspondence should be addressed to Jinghui Tang; tangjinghui@ysu.edu.cn
}

Received 27 November 2021; Revised 29 December 2021; Accepted 3 January 2022; Published 31 January 2022

Academic Editor: Deepak Kumar Jain

Copyright ( $\odot 2022$ Jinghui Tang et al. This is an open access article distributed under the Creative Commons Attribution License, which permits unrestricted use, distribution, and reproduction in any medium, provided the original work is properly cited.

\begin{abstract}
This article mainly studies the innovation of borderless integrated financial management in big data social media in the era of wireless communication networks. For evaluating company A's financial sharing capabilities, five first-level indicators are divided into four dimensions: quality, efficiency, cost, and safety, and are allowed to score the financial sharing center capabilities. First of all, system integration takes performance appraisal as the core, and through the establishment of a reasonable appraisal system, performance appraisal for the members of the financial team is carried out. Secondly, team members need to accept two-way leadership, two-way assessment, and two-way incentives from the finance and business departments. The experimental factors were analyzed, and the results showed that the cumulative variance contribution rate with common factors reached $89.339 \%$. The importance of the first-level indicators is in order of process reengineering (27.08\%), operation management (22.33\%), information system (20.24\%), personnel management (17.178\%), and strategic planning $(12.46 \%)$.
\end{abstract}

\section{Introduction}

Financial management refers to the management of asset purchase (investment), capital financing (funding), cash flow (working capital) in operation, and profit distribution under certain overall goals. Financial management is an integral part of corporate management. It is an economic management task that organizes corporate financial activities and handles financial relationships in accordance with financial laws and regulations and the principles of financial management. Simply put, financial management is an economic management task for organizing corporate financial activities and handling financial relationships.

Financial planning helps companies set guidelines to develop operational and financial plans. Rationalize the company's key objectives and take into account capital investment. The company's goals are transformed into tangible financial indicators. Investment decisions and goals produce integrated financial statements, linking financial goals and financial indicators. Then, the entire organization operates around these goals and indicators.
The use of big data in financial management is an inevitable trend under technological and economic development. Widajatun and Kristiastuti aim to use questionnaires [1]. Siminică et al.'s research aims firstly to prove that financial management is an integral part of tactical management and secondly to reconfigure the conceptual configuration of financial management in addition to strategic management and operational management, as an element of tactical management. The method they use is a combination of rational observation, comparison, and metaanalysis $[2,3]$. Lei et al. believe in the traditional intelligent diagnosis method; it depends on prior knowledge and diagnosis expertise to manually extract features. Such a process utilizes human creativity, with the motor bearing data set and the locomotive bearing data set. Although their research method has high accuracy, it lacks specific system test content [4].

Through the use of big data technology, this paper can help the financial department to establish a more effective system. Through the investigation of the current situation of financial management in China, it finds that it cannot adapt 
to the development of new economy and puts forward the corresponding changes in the field of financial management so as to provide directional suggestions for the financial management innovation of Chinese enterprises in the era of new economy. The experimental part analyzes the performance of the financial management model and explores its expansion performance to ensure the stable operation of the model.

\section{Borderless Integrated Financial Management Innovation}

2.1. Wireless Communication Network. The physical layer key distribution in wireless communication networks is an information-theoretic security encryption method based on the randomness of channel characteristics, which is different from the traditional public key or private key, which is based on computational security (traditional public key cryptosystem based on PKI). Moreover, the public key calculation burden of asymmetric encryption in the traditional classic encryption method is too large, and the distribution and management of the private key face various problems. Different from the traditional key generation method, the key generated by the natural random characteristics of the wireless channel has a high security strength. The key distribution at the physical layer is still a lightweight key distribution method, which can be realized without the assistance of a third party. Based on the natural attribute characteristics of the protocol datagram, the management frame data and data frame data of the unknown protocol datagram are effectively distinguished, and the management frame data of the protocol is marked and extracted. The protocol management frame data set extracted in this part is used as the original data object of the protocol semantic mining, (1) demand analysis, (2) script writing, (3) demand verification, and (4) Demand submission), which makes the further semantic analysis of the protocol data report more focused and targeted, removes the relatively weak redundant data associated with the protocol mode part, and effectively improves the efficiency of protocol semantic mining. The wireless communication network structure is shown as in Figure 1.

This is an information exchange where individual users are the source of information $[5,6]$.

For $i=1,2, \ldots, m$,

$$
d_{i j}=\left\|x_{i}-\mu_{j}\right\|_{2}^{2}
$$

Recalculating the new centroid distance, the expression is

$$
\mu_{j}=\frac{1}{\left|c_{j}\right|} \sum_{x \in c_{j}} x
$$

The definition of accuracy is

$$
\mathrm{AC}=\frac{\sum_{i=1}^{n} \delta\left(r_{i}, \operatorname{map}\left(l_{i}\right)\right)}{n},
$$

where AC is accuracy.
The mutual information measure is

$$
\operatorname{MI}\left(C, C^{\prime}\right)=\sum_{c_{i} \in C, c_{j}^{\prime} \in C^{\prime}} p\left(c_{i}, c_{j}^{\prime}\right) * \log \frac{p\left(c_{i}, c_{j}^{\prime}\right)}{p\left(c_{i}\right) p\left(c_{j}^{\prime}\right)} \text {. }
$$

The expression of the normalized mutual information is as follows:

$$
\begin{aligned}
\operatorname{NMI}\left(C, C^{\prime}\right) & =\frac{\operatorname{MI}\left(C, C^{\prime}\right)}{\max \left(H(C), H\left(C^{\prime}\right)\right)}, \\
R & =\frac{\operatorname{cov}(x, y)}{\sqrt{D(x)} * \sqrt{D(y)}}, \\
\hat{e} & =\frac{1}{N} \sum_{i=1}^{N} I_{\left\{S\left(x_{i}\right) \geq \gamma\right\}} \frac{f(x, p)}{f(x, q)}, \\
v^{*} & =\arg \max _{v} E_{u} I_{\{S(X) \geq \gamma\}} \ln f(X ; v), \\
E(u, v) & =\sum_{x, y} w(x, y)[I(x+u, y+v)-I(x, y)]^{2}, \\
M & =\sum_{x, y} w(x, y)\left[\begin{array}{cc}
I_{x}^{2} & I_{x} I_{y} \\
I_{x} I_{y} & I_{y}^{2}
\end{array}\right], \\
G(x, y) & =\frac{1}{2 \pi \sigma^{2}} e^{-\left(x^{2}+y^{2} / 2 \sigma^{2}\right)} \\
G_{x}(i, j) & =\frac{1}{2}(I(i, j+1)-I(i, j)+I(i+1, j+1)-I(i+1, j)), \\
G_{y}(i, j) & =\frac{1}{2}(I(i, j)-I(i+1, j)+I(i, j+1)-I(i+1, j+1)) .
\end{aligned}
$$

Through $G_{x}(i, j)$ and $G_{y}(i, j)$, the gradient amplitude $G(i, j)$ and the gradient direction $\theta(i, j)$ can be obtained [7]:

$$
\begin{aligned}
G(i, j) & =\sqrt{G_{x}^{2}(i, j)+G_{y}^{2}(i, j)}, \\
\theta(i, j) & =\operatorname{arc}\left(\frac{G_{x}(i, j)}{G_{y}(i, j)}\right)
\end{aligned}
$$

where $x$ represents the centroid distance, $G$ is the gradient amplitude, and $\theta$ is the gradient direction.

The candidate edge points are selected through the double threshold method to obtain the image edge $[8,9]$.

2.2. Social Media. Although sharing is a common behavior of Internet users, there are significant differences in the specific performance. The types of information easily spread on different platforms are different, and the types of information shared by users with different personalities are also different. Today's social media is mostly composed of the following three elements: content portal, relationship portal, and service portal, such as WeChat. Now, WeChat has become an important tool for us to maintain online and offline relationships. Users can publish text, pictures, and videos through the circle of friends, and their friends can like, comment, share, and forward [10]. Nowadays, there are countless sunbathers in WeChat and microblog sharing their life or work status and some user original content every 


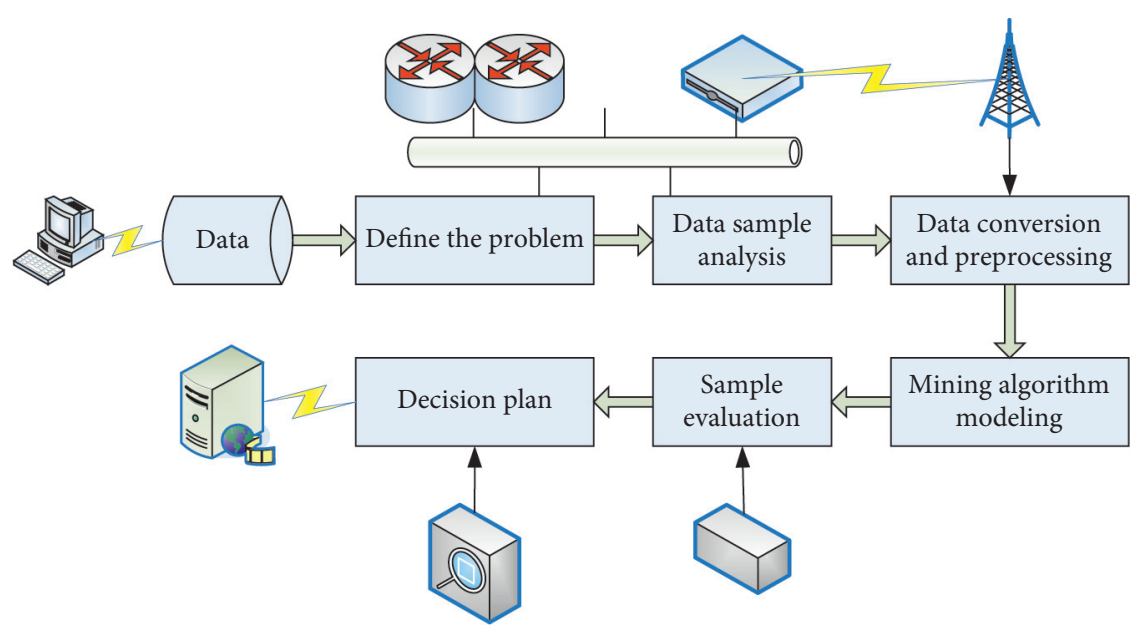

FIgURE 1: Wireless communication network structure.

day. When we see our favorite movies and meet our favorite snacks, when we are in a good mood, we will think of a circle of friends. When we are in a low mood because of something, we will also express our mood at this moment in the circle of friends' microblog or space. Through these social platforms, we can roughly judge a person's mood in a day. Social networking is the most basic needs of human beings, and social networking platform greatly meets our social needs. Here, we can make friends with the same interests and hobbies and maintain our friends, classmates, and work relationships at all times $[11,12]$.

\subsection{Borderless Integrated Financial Management Innovation.} The construction of a financial management innovation model adaptation model is a process of continuous revision based on the internal and external environmental factors of the enterprise under the joint efforts of the innovation participants and entrepreneurs [13, 14]. Financial management innovation refers to a qualitative leap that has been achieved due to the influence and changes of related factors after the gradual accumulation of financial management in enterprises. This alternate evolution process is the inheritance and innovation process of corporate financial management. From this point of view, the construction of a financial management innovation strategy adaptation model belongs to the category of organizational evolution. Due to the explosion of information and the development of emerging information technologies, companies have a deeper understanding of the value of data, and they also face challenges in data storage and processing $[15,16]$.

\section{Borderless Integrated Financial Management Innovation Experiment}

3.1. Construction of the Network Platform. The nature of the problem: in addition, each subsystem can also be integrated, through its internal connections and interactions (build the system platform according to the customer's functional requirements for the system), to provide effective support for the development of the enterprise $[17,18]$.
3.2. Evaluation Index. For evaluating company A's financial sharing capabilities, five first-level indicators are divided into four dimensions, are allowed to score the financial sharing center capabilities [19]. The evaluation criteria are mainly reflected in key structures, such as sharing capabilities and data interaction speed.

\subsection{Construction of Integrated Financial Management Model.} Through the protection of the support system and the operation of key processes, various valuable dynamic knowledge within the organization can be managed. Different types of subject members conduct knowledge management, produce knowledge performance, and ultimately achieve the purpose of enhancing the marketing ability and competitiveness of the enterprise. Financial management is only carried out internally, and it has become increasingly unable to meet the needs of enterprise development [20].

3.4. Evaluation System. On the basis of the original financial management organization structure, we need to add special departments in the financial management organization to manage financial data, nonfinancial data, and other business data and manage the development platform of financial big data center $[21,22]$. Valuable and meaningful information is provided for enterprises from massive data. Through the hospital revenue and expenditure percentage, the comprehensive budget management system of the hospital can carry out centralized budget, such as centralized management in drug procurement, laboratory test, inspection, health, diagnosis and treatment, personnel funds, and so on; through the centralized setting of budget management, it is convenient for the preparation and audit of comprehensive budget to the upper level and the lower level $[23,24]$.

3.5. Innovative Design of Financial Management Model. In modern financial management theory, the goal of financial management has changed from maximizing profit and maximizing shareholder value to maximizing corporate 
value. Under the industry-financial integration model, the goal of corporate financial management is still to maximize corporate value. Under this model, corporate financial management activities and corporate strategic management tend to be integrated to improve the strategic position of financial goals. First of all, system integration takes performance appraisal as the core, and through the establishment of a reasonable appraisal system, performance appraisal for the members of the financial team. Secondly, team members need to accept two-way leadership, two-way assessment, and two-way incentives from the finance and business departments $[25,26]$.

\section{Analysis of Financial Management Innovation Model}

4.1. Analysis of Fund Management Application Mode. The explanatory total variables of factor analysis are shown in Table 1. Cumulative variance contribution rate when extracting 5 common factors reaches $89.339 \%$, indicating that it is suitable to take 5 common factors. If the financial information system wants to be more intelligent, it must combine the cloud computing capabilities of the hospital cloud platform. The cloud platform can strengthen the information transmission and sharing between the various subsystems of the information system. The information department needs to plan the development needs of the hospital, try to display the collected data on the platform, and ensure that the collected data can be reprocessed, processed, and analyzed so that data can be shared and utilized in the cloud platform. The operation of the cloud platform must be based on the collection of data from the entire medical industry so that it can collect all the data of income and expenditure, prescription management, drug management, medical record management, financial management, electronic medical records, and nurse workstations. Only with comprehensive internal and external data information can the platform be truly used by hospitals.

For Hadoop and BitDew-MR, the throughput test results of setting the number of concurrent threads on different clients and metadata operation interval are shown in Figures 2 and 3. However, compared with Hadoop, the results show that BitDew-MR has stronger scalability.

The performance test results of fault tolerance scenarios are shown in Table 2. In Hadoop job test, for the first failure mode, when the simulation framework terminates the running tasks on all compute nodes, the jobtracker is rescheduled to the 50 node. For the second failure mode, jobtracker reschedules all map tasks that have been successfully executed and are being executed on the failed tasktrackers indiscriminately. This means that the contribution of tasks executed by all computing nodes before the failure point to the execution progress of the whole job is zero, resulting in the fact that the final execution time of the job is almost twice of the benchmark execution time. In the third failure mode, Hadoop terminates the operation of the job and marks it as failure due to the permanent loss of some input data fragments.
Knowing the relevant information can inform the decision-making of company management. While developing and researching, companies should also relax their sights and develop specialized financial early-warning models. More than this, the changes in the market economy environment and the development and changes of the industry should also be taken into account when formulating the financial early warning system. With the changes in the environment, it constantly adjusts its own financial early warning system to maintain its timeliness and high forecasting ability.

The survey results of the relative importance of the firstlevel evaluation indicators are shown in Table 3 and Figure 4. First, use EXCEL to calculate the geometric mean and the geometric mean of each row, and calculate the weight percentage $(\mathrm{Wi})$. Secondly, use the MMULT function to calculate the product of the AWi matrix, and obtain the result of each row of $\mathrm{AWi} / \mathrm{Wi}$ and the sum of 25.1737. The importance of the first-level indicators is as follows: process reengineering $(27.08 \%)$, operation management $(22.33 \%)$, information system (20.24\%), personnel management (17.178\%), and strategic planning (12.46\%).

\subsection{Evaluation and Analysis of Financial Sharing Ability.} The characteristic roots and contribution rates of factors are shown in Table 4. The feature root is greater than 1; that is, the maximum variance rotation method is used to extract factors from the observation indicators in the three scales, 7 driving factor variables, and 15 supporting/impeding factor variables and finally found $85.744 \%$ and $86.225 \%$ of the information. By establishing big data assets, analyzing user behavior and user usage effects, it can help companies analyze and mine the behavior habits of these customers so that these big data assets can give full play to their role and effectively predict user behavior habits through a large number of data assets and trends. More humane, targeted products and sales policies should be provided, as well as assurance for the quality of accounting information.

With the continuous development of the enterprise, the scale of the enterprise is getting larger and larger, and the comprehensive ability of the enterprise is becoming stronger and stronger. When the enterprise develops to a certain stage, its own management ability, capital ability, and technical ability become strong enough, and the focus of the enterprise's senior management is also transferred from product production to management innovation, especially financial management innovation; we can use the remaining energy to change the financial management mode and ideas, improve the financial management ability, and then form the support for the enterprise development strategy. At the same time, at this time, some enterprises will form the spillover of financial management innovation ability; that is, the current enterprise financial management can not only meet the needs of enterprise development strategy, but also use their own strong internal resources to carry out active and independent reform and innovation of financial management so as to lead the development strategy of enterprises. The comparison of operation steps is shown in 
TABLE 1: Total explanatory variables of factor analysis.

\begin{tabular}{|c|c|c|c|c|c|c|c|c|}
\hline \multicolumn{3}{|c|}{ Initial factor situation } & \multicolumn{3}{|c|}{ Initial state factor extraction } & \multicolumn{3}{|c|}{ Factor extraction after rotation } \\
\hline Total & $\%$ of variance & Cumulative $\%$ & Total & $\%$ of variance & Cumulative\% & Total & $\%$ of variance & Cumulative\% \\
\hline 5.13 & 32.10 & 32.10 & 5.13 & 32.10 & 32.10 & 4.34 & 27.14 & 27.14 \\
\hline 3.87 & 24.23 & 56.33 & 3.87 & 24.23 & 56.33 & 3.54 & 22.15 & 49.29 \\
\hline 2.04 & 12.76 & 69.10 & 2.04 & 12.76 & 69.10 & 2.22 & 13.88 & 63.18 \\
\hline 1.87 & 11.72 & 80.82 & 1.87 & 11.72 & 80.82 & 2.10 & 13.12 & 76.31 \\
\hline 1.36 & 8.51 & 89.33 & 1.36 & 8.51 & 89.33 & 2.08 & 13.02 & 89.33 \\
\hline
\end{tabular}

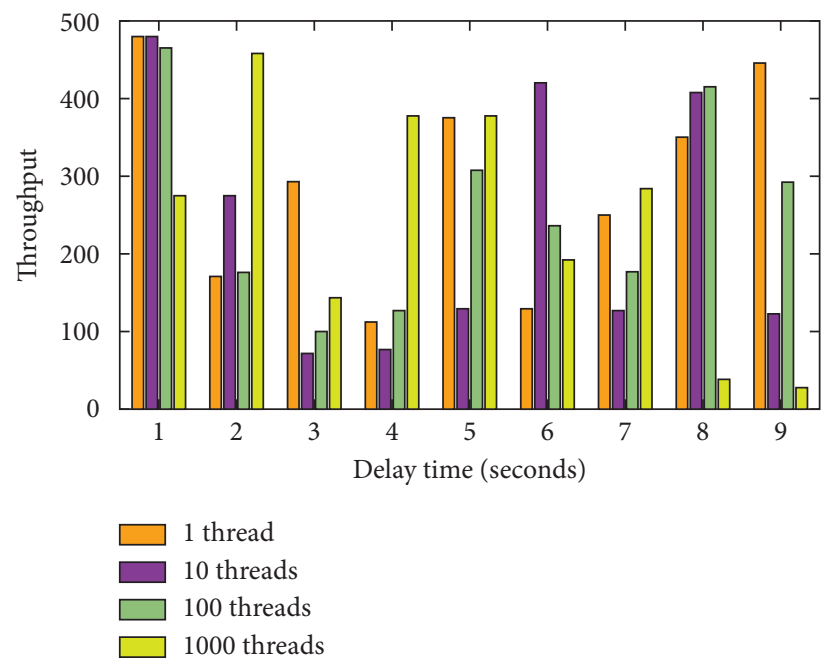

FIgURE 2: Hadoop core system service scalability test results.

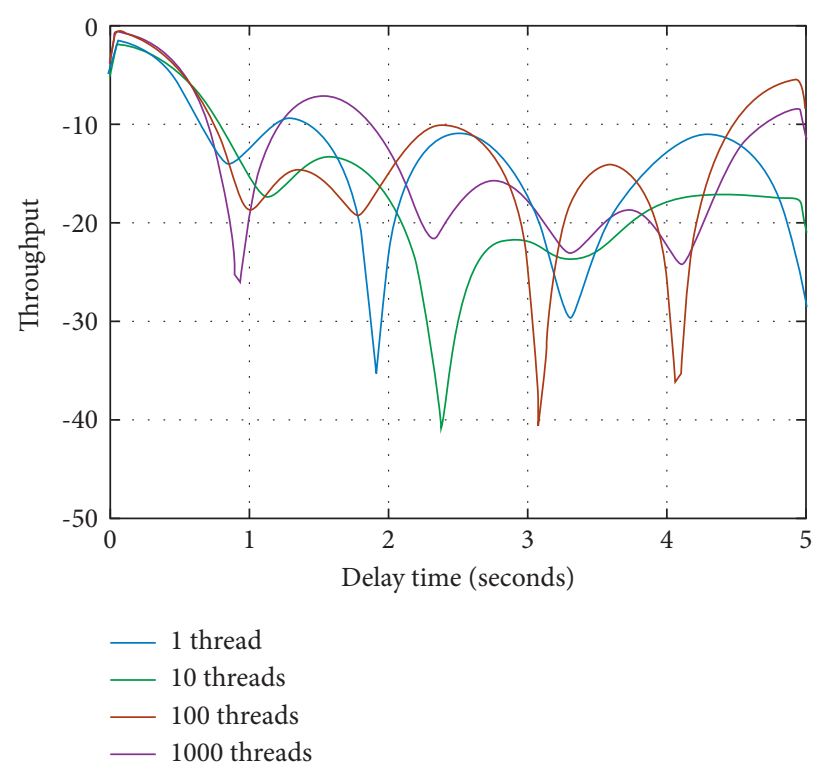

FIgUre 3: The scalability evaluation of BitDew core system services.

TABLE 2: Performance test results of fault tolerance scenarios.

\begin{tabular}{|c|c|c|c|c|c|c|c|c|c|c|}
\hline \multicolumn{3}{|c|}{ Job failure point progress } & $12.5 \%$ & $25 \%$ & $37.5 \%$ & $50 \%$ & $50 \%$ & $75 \%$ & $87.5 \%$ & $100 \%$ \\
\hline \multirow{5}{*}{ Hadoop } & \multirow{2}{*}{ Task failure } & Number of reexecuted map tasks & 50 & 50 & 50 & 50 & 50 & 50 & 50 & 50 \\
\hline & & Execution time & 425 & 425 & 423 & 427 & 426 & 429 & 431 & 453 \\
\hline & \multirow{3}{*}{ Task tracker failure } & Number of reexecuted map tasks & 50 & 100 & 150 & 200 & 250 & 300 & 350 & 400 \\
\hline & & Execution time & 816 & 823 & 809 & 815 & 820 & 819 & 812 & 814 \\
\hline & & Node failure & & & & Job & ilure & & & \\
\hline \multirow{2}{*}{ BitDew-MR } & \multirow{2}{*}{ Node failure } & Number of reexecuted map tasks & 50 & 0 & 50 & 0 & 50 & 0 & 50 & 0 \\
\hline & & Execution time & 450 & 411 & 389 & 351 & 331 & 299 & 279 & 247 \\
\hline
\end{tabular}


TABLE 3: Survey results of relative importance of first-level evaluation indicators.

\begin{tabular}{lccccc}
\hline $\begin{array}{l}\text { First-level evaluation } \\
\text { index }\end{array}$ & $\begin{array}{c}\text { Strategic } \\
\text { planning A }\end{array}$ & $\begin{array}{c}\text { Information system } \\
\text { B }\end{array}$ & $\begin{array}{c}\text { Process } \\
\text { reengineering C }\end{array}$ & $\begin{array}{c}\text { Operation } \\
\text { management D }\end{array}$ & $\begin{array}{c}\text { Personnel } \\
\text { management E }\end{array}$ \\
\hline Strategic planning A & 1 & 0.61 & 0.49 & 0.56 & 0.63 \\
Information system B & 1.64 & 1 & 0.87 & 1.10 & 1.34 \\
Process reengineering & 2.03 & 1.15 & 1 & 1 & 1.24 \\
C & 1.79 & 1.13 & 0.91 & 0.86 & 1.16 \\
$\begin{array}{l}\text { Operation management } \\
\text { D }\end{array}$ & 1.59 & 0.75 & 0.80 & 0.86 \\
Personnel management & & & & 1 \\
E & & & & \\
\hline
\end{tabular}

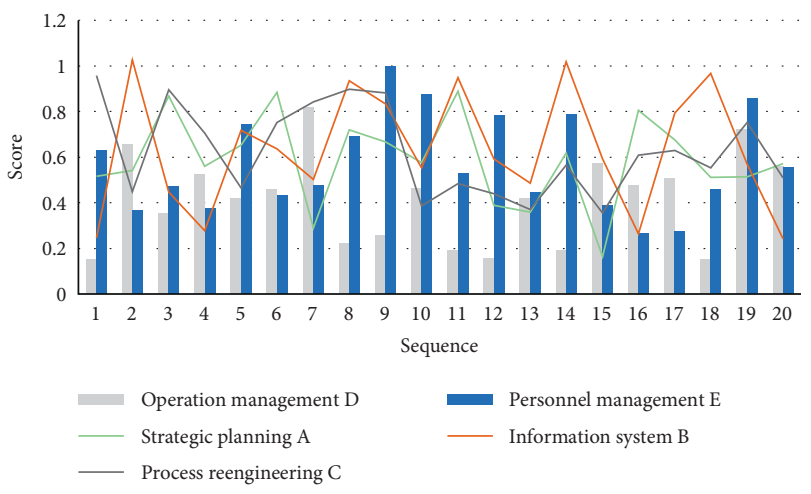

FIGURE 4: Survey results of the relative importance of first-level evaluation indicators.

Figure 5. Because the control group can only display 1 to 2 pieces of information on one screen, the longer the information is searched, the more times the mouse wheel is used, resulting in a very high number of operation steps of individual tasks. Through the comparison of operation steps, it can be found that the information can be quickly and effectively searched through the quick positioning of time line and the overview presentation of information (multiple pieces of information are displayed on one screen).

The financial management of the group is responsible for maximizing the value of the enterprise. It needs to explain the operating results to investors and improve the management level. It needs to show the operating performance, operating risk, financial status and profitability of different member units, industry sectors, and responsibility centers and evaluate their performance through multi perspective evaluation system. However, from the perspective of value chain, if the financial management of the group is in the information island environment between the group and its members, facing the huge organizational structure and complex hierarchical relationship of the group, and the situation of manual collection and summary of information from bottom to top, it is unable to combine, distribute, and release the financial and nonfinancial information that meets the multiperspective analysis, which makes it difficult for the group to objectively evaluate its performance from multiperspective. This affects the power of group members to create value for the group, and the group cannot allocate resources reasonably, which ultimately affects the competitiveness. The intraclass mean difference test is shown in Figure 6.
For higher vocational colleges, if they want to effectively manage state allocated funds and self-raised funds and improve the utilization rate, then improving their own financial management level becomes a necessary means and method. To improve the level of financial management, we need to innovate the financial management model. For these items to be revised, the school's financial department must review the budget and revise the budget carefully. At the same time, for the results of the budget, the financial department should also do a good job of assessment and evaluation. In the execution of the budget, it is necessary to track the execution of the budget in time and do a good job of relevant records and analysis. When there is a budget deviation, it is necessary to pass the meeting of principals, attach great importance to it, and study the countermeasures. The implementation of the budget should be evaluated at the end of the budget work to find out the problems and play a positive role in the next cycle of financial budget work. The abnormal detection results on the data stream are shown in Table 5 and Figure 7.

4.3. Analysis of Evaluation System. The convergence curves of CAR and RSVM are shown in Figure 8. By moving as much work as possible to the offline stage, this reduces the average time cost of online recommendation. We conducted an online recommendation test on 200 test cases and spent a total of 125.768 seconds, which means that each recommendation takes 0.629 seconds on average, which is acceptable and effective. The development of knowledge management provides the possibility for external parties to enter the marketing knowledge management. The emergence of knowledge management provides a good way to make full use of enterprise internal knowledge. The development of information technology provides technical means for knowledge management inside and outside the enterprise as a system. Since the outside of the enterprise is the growth point of enterprise competitiveness, it must be paid attention to and researched. As the marketing environment changes, the scope of marketing knowledge management must be expanded. The development of knowledge management methods and information technology provides the feasibility for the external members of the enterprise to incorporate the knowledge management process.

The comparison of the evaluation results between the models is shown in Table 6 and Figure 9. The MSE obtained by the CNN-XGBoost algorithm used in this paper is 0.9175 , 
TABLE 4: Factor characteristic roots and contribution rate.

\begin{tabular}{lccccccccc}
\hline \multirow{2}{*}{ Main factor } & \multicolumn{3}{c}{ Driving factors } & \multicolumn{3}{c}{ Support/obstacle } & \multicolumn{4}{c}{ Entrepreneur oriented } \\
& 1 & 2 & 3 & 1 & 2 & 3 & 4 & 1 & 2 \\
\hline Characteristic root & 2.52 & 2.02 & 1.41 & 4.96 & 3.46 & 2.60 & 1.82 & 1.86 & 1.39 \\
Contribution rate \% & 36.01 & 28.95 & 20.18 & 33.12 & 23.12 & 17.36 & 12.16 & 37.20 & 27.86 \\
Cumulative contribution rate \% & 36.01 & 64.97 & 85.15 & 33.12 & 56.25 & 73.61 & 85.74 & 37.20 & 65.06 \\
\hline
\end{tabular}

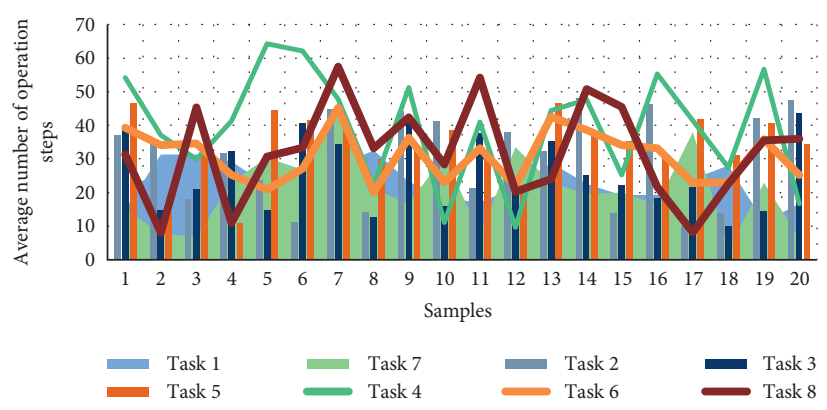

Figure 5: Comparison of operation steps.

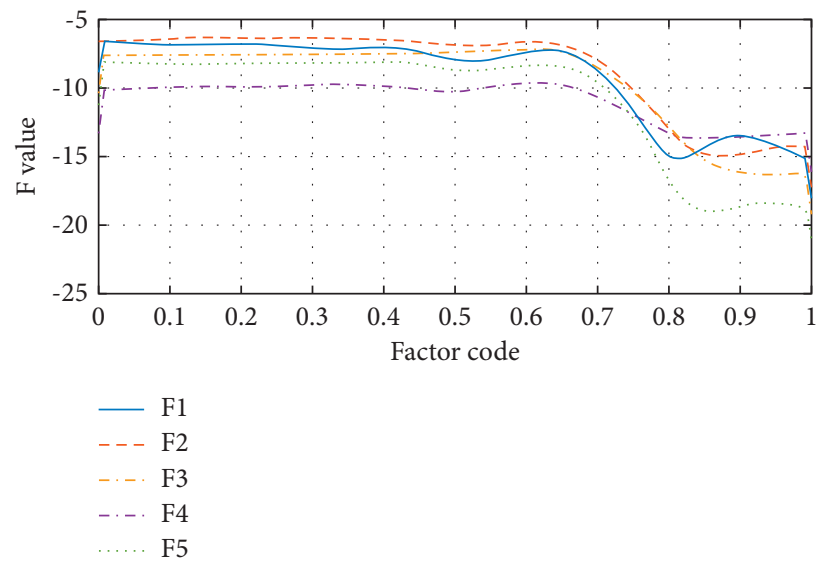

FIgURE 6: Tests for differences in means within classes.

TABLE 5: Anomaly detection results on the data stream.

\begin{tabular}{lccc}
\hline Observed value & Smooth value & Lower limit & Upper limit \\
\hline 614 & 406.1302 & 337.0840 & 500.8360 \\
794 & 530.8521 & 314.6201 & 552.1492 \\
813 & 688.7408 & 304.1737 & 590.7152 \\
807 & 763.2963 & 301.4154 & 619.1561 \\
754 & 789.5186 & 305.2033 & 635.6242 \\
492 & 768.2074 & 311.7113 & 630.5554 \\
520 & 602.4830 & 318.4364 & 626.9830 \\
868 & 552.9932 & 317.8351 & 652.2899 \\
490 & 741.9973 & 323.3339 & 647.0904 \\
428 & 590.7989 & 326.3350 & 640.7239 \\
\hline
\end{tabular}

the MAE is 0.5592 , and the SPR is 0.9187 . The three evaluation indicators are far superior to the other 8 algorithms. Through experimental comparison, it is found that the regression algorithm based on multimodal depth features has achieved certain improvement in the three evaluation indicators of MSE, MAE, and SPR. Because the preprocessed data is relatively rough and extremely sparse, the multimodal feature information is obscure, chaotic, and weak. After the supervised learning of the convolutional neural network, the original multimodal features are mapped to the ordered and prominent multimodal deep fusion feature space, thereby improving the performance of the regression. 


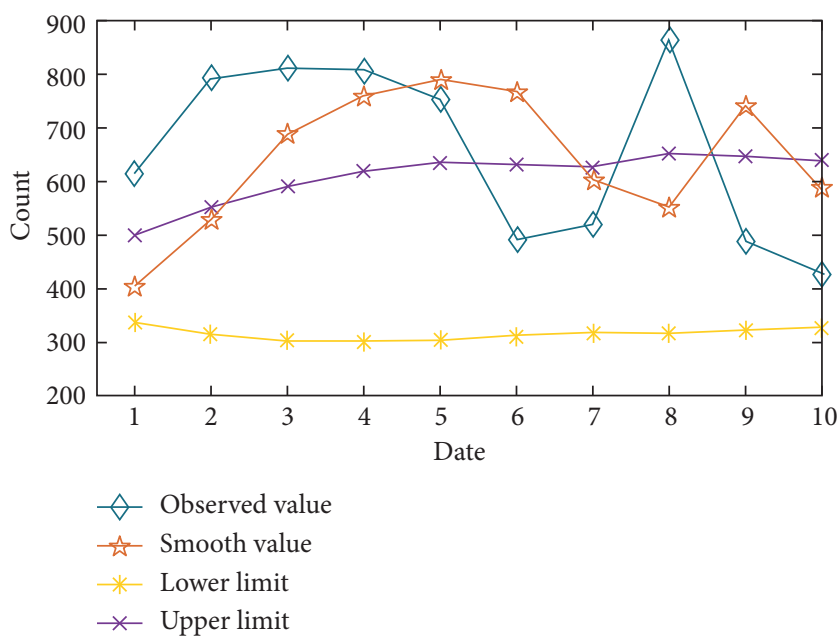

FIgUre 7: Anomaly detection results on the data stream.

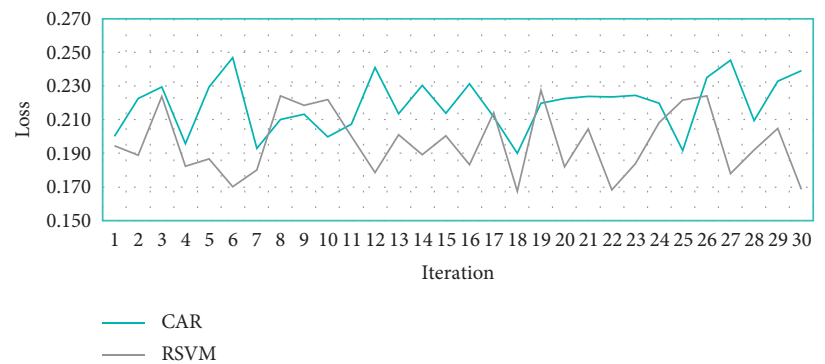

FIgURe 8: Convergence curves of CAR and RSVM.

TABLE 6: Comparison of evaluation results between models.

\begin{tabular}{|c|c|c|c|c|c|c|}
\hline & MSE & MSE (CNN) & MAE & MAE (CNN) & SPR & SPR (CNN) \\
\hline XGBoost & 1.0261 & 0.9287 & 0.6147 & 0.5592 & 0.8896 & 0.9175 \\
\hline Bagging & 1.5063 & 1.3362 & 0.7152 & 0.6554 & 0.8371 & 0.8728 \\
\hline GBR & 2.0698 & 1.7865 & 1.1963 & 0.8313 & 0.7002 & 0.7812 \\
\hline DTR & 2.9570 & 2.3895 & 1.0655 & 0.8391 & 0.7101 & 0.7831 \\
\hline $\mathrm{ADR}$ & 3.2954 & 2.5176 & 1.1032 & 0.8374 & 0.7083 & 0.7862 \\
\hline LR & 2.5491 & 1.9050 & 1.3627 & 1.0930 & 0.71127 & 0.7820 \\
\hline KNN & 2.4175 & 1.9881 & 0.9253 & 0.7563 & 0.7795 & 0.8254 \\
\hline RFR & 3.1690 & 2.4532 & 1.0852 & 0.8311 & 0.7020 & 0.7881 \\
\hline ETR & 2.9141 & 2.5002 & 1.0788 & 0.8303 & 0.7118 & 0.7884 \\
\hline
\end{tabular}

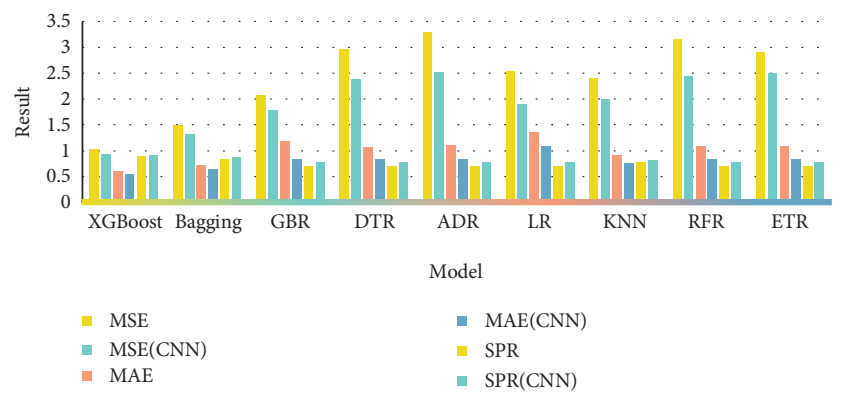

Figure 9: Comparison of evaluation results between models.

\section{Conclusions}

Wireless communication is a way of electromagnetic wave communication, which breaks through the restriction of fixed geographical location of receiving and sending end by wired communication, and expands people's communication range. The most commonly used wireless communications in life are cellular mobile communications systems and wireless broadband access systems. They provide people with content-rich services, and their development has changed people's daily communication methods. The risk management system implemented in the early stage is 
difficult to meet the needs of the company's development. Therefore, the company must find more management methods, use big data technology, and manage budgets. And risk management actively identifies internal and external risks and reflects the prevention and control of these risks in the design of enterprise operation systems.

As an inevitable path for the development of corporate financial management, to give play to the applicability and advantages of the centralized financial management model, the company needs to provide a good operating environment, ensure the effective operation of the new management model, and coordinate every operation, analysis, and process in the financial work. Improve the original management method; regularly learn and update the new management mode. In addition, with the advent of the digital age, how to apply advanced information technology to financial sharing is also a problem that requires continuous consideration. In addition, the company is developing. In order to expand the scale and reduce risks, the company may expand its business across industries. Then, whether the current financial sharing can support the expansion of the enterprise and whether the new business needs to be optimized for the system are all financial sharing that need continuous improvement reason.

Therefore, corporate managers, decision-makers, financial staff, and business personnel all need to change their thinking mode, management methods, and management techniques.

\section{Data Availability}

No data were used to support this study.

\section{Conflicts of Interest}

The authors declare that they have no conflicts of interest regarding the publication of this study.

\section{Acknowledgments}

This work was supported by Hebei Social Science Fund Research on Influencing Factors of Market Value Management of High-Quality Listed Companies (no. HB21GL024).

\section{References}

[1] V. W. Widajatun and F. Kristiastuti, "The effect of regional financial supervision, accountability and transparency of regional financial management on local government performance," Budapest International Research and Critics Institute (BIRCI-Journal): Humanities and Social Sciences, vol. 3, no. 4, pp. 2966-2974, 2020.

[2] M. Siminică, A. G. Motoi, and A. Dumitru, "Financial management as component of tactical management," Polish Journal of Management Studies, vol. 15, no. 1, pp. 206-217, 2017.

[3] Y. Zhang, M. Qiu, C.-W. Tsai, M. M. Hassan, and A. Alamri, "Health-CPS: healthcare cyber-physical system Assisted by cloud and big data," IEEE Systems Journal, vol. 11, no. 1, pp. 88-95, 2017.
[4] Y. Lei, F. Jia, J. Lin, S. Xing, and S. X. Ding, "An intelligent fault diagnosis method using unsupervised feature learning towards mechanical big data," IEEE Transactions on Industrial Electronics, vol. 63, no. 5, pp. 3137-3147, 2016.

[5] J. Brinckmann, S. Salomo, and H. Georg Gemuenden, "Financial management competence of founding teams and growth of new technology-based firms," Entrepreneurship: Theory and Practice, vol. 35, no. 2, pp. 217-243, 2017.

[6] C. Chapman, "ERIM research seminar in financial management: doing qualitative field research in management accounting: positioning data to contribute to theory," Accounting, Organizations and Society, vol. 31, no. 8, pp. 819-841, 2017.

[7] S. Megawati, M. F. Ma'ruf, E. H. Fanida, F. Niswah, and T. A. Oktariyanda, "Strengthening family resilience through financial management education in facing the covid-19 pandemic," Journal La Bisecoman, vol. 1, no. 5, pp. 8-15, 2020.

[8] N. Muttaqiin, "Analysis of household financial management for work from home affected employees (case study on employees of insurance industry companies in surabaya)," Accounting and Management Journal, vol. 4, no. 2, pp. 105$112,2020$.

[9] A. Lalbiakzuali and N. V. R. Jyoti Kumar, "Financial management in Zoram Industrial Development Corporation Ltd. (ZIDCO)," International Journal of Advanced Research, vol. 8, no. 5, pp. 378-388, 2020.

[10] U. Hasanah and M. Silitonga, "Financial management, time management, and wives's subjective well-being on wives working full-time," International Journal of Psychosocial Rehabilitation, vol. 24, no. 3, pp. 1741-1749, 2020.

[11] W. M. Y. Jaeng, I. M. S. Suardikha, and I. G. A. N. Budiasih, "Effect of use of regional financial management information systems on individual performance in BPKAD Sikka Regency," International Research Journal of Management, IT and Social Sciences, vol. 6, no. 6, pp. 188-193, 2019.

[12] K. Huh, S. Kim, and S. Kim, "A structural analysis of financial stress, financial management self-confidence and financial satisfaction," Consumer Policy and Education Review, vol. 14, no. 1, pp. 149-173, 2018.

[13] Y. Wang, "Study on supply and demand model of financial management talents in Shandong province with data mining," Boletin Tecnico/Technical Bulletin, vol. 55, no. 16, pp. 212-219, 2017.

[14] F. Hrza, "The effect of the financial crisis on Czech municipal financial management: can a future crisis be prevented?" Journal of Management, vol. 12, no. 1, pp. 143-151, 2017.

[15] Y. J. Loke, "The influence of socio-demographic and financial knowledge factors on financial management practices of Malaysians," International Journal of Business \& Society, vol. 18, no. 1, pp. 33-50, 2017.

[16] S. Sazonov, E. Kharlamova, I. Ezangina, N. Gorshkova, M. Kovazhenkov, and E. Polyanskaya, "Theory and methodology of the financial management of the regional supporting university," Journal of Advanced Research in Law and Economics, vol. 8, no. 1, pp. 211-219, 2017.

[17] R. Zimpel, F. I. Bánkuti, M. A. Zambom, K. C. Kuwahara, and S. M. S. Bánkuti, "Characteristics of the dairy farmers who perform financial management in Paraná State, Brazil," Revista Brasileira de Zootecnia, vol. 46, no. 5, pp. 421-428, 2017.

[18] J. Surujlal, "Influence of organizational support on retirement planning and financial management of professional soccer players," Polish Journal of Management Studies, vol. 13, no. 2, pp. 164-174, 2016. 
[19] J. Špička and S. R. Kontsevaya, "Differences of financial management strategy of central European and Russian milk processors," AGRIS On-Line Papers in Economics and Informatics, vol. 8, no. 1, pp. 89-102, 2016.

[20] G. S. Larson, C. Carey, J. Grarup et al., "Lessons learned: infrastructure development and financial management for large, publicly funded, international trials," Clinical Trials, vol. 13, no. 2, pp. 127-136, 2016.

[21] N. Asandimitra and A. Kautsar, "The influence OF financial information, financial self efficacy, and emotional intelligence to financial management behavior OF female lecturer," $\mathrm{Hu}$ manities \& Social Sciences Reviews, vol. 7, no. 6, pp. 11121124, 2020.

[22] E. Baccarelli, N. Cordeschi, A. Mei, M. Panella, M. Shojafar, and J. Stefa, "Energy-efficient dynamic traffic offloading and reconfiguration of networked data centers for big data stream mobile computing: review, challenges, and a case study," Computers \& Chemical Engineering, vol. 91, no. 2, pp. 182194, 2016.

[23] J. W. Xue, X. K. Xu, and F. Zhang, "Big data dynamic compressive sensing system architecture and optimization algorithm for internet of things," Discrete and Continuous Dynamical Systems-Series S, vol. 8, no. 6, pp. 1401-1414, 2017.

[24] L. Kuang, F. Hao, L. T. Yang, M. Lin, C. Luo, and G. Min, "A tensor-based approach for big data representation and dimensionality reduction," IEEE Transactions on Emerging Topics in Computing, vol. 2, no. 3, pp. 280-291, 2017.

[25] S. Wang, J. Wan, D. Zhang, D. Li, and C. Zhang, "Towards smart factory for industry 4.0: a self-organized multi-agent system with big data based feedback and coordination," Computer Networks, vol. 101, no. 6, pp. 158-168, 2016.

[26] A. Gani, A. Siddiqa, S. Shamshirband, and F. Hanum, "A survey on indexing techniques for big data: taxonomy and performance evaluation," Knowledge and Information Systems, vol. 46, no. 2, pp. 241-284, 2016. 